\title{
Traditional and molecular detection methods reveal intense interguild competition and other multitrophic interactions associated with native entomopathogenic nematodes in Swiss tillage soils
}

\author{
Raquel Campos-Herrera • Geoffrey Jaffuel • Xavier Chiriboga • \\ Rubén Blanco-Pérez • Marie Fesselet • Vladimír Půža • \\ Fabio Mascher • Ted C. J. Turlings
}

Received: 10 October 2014 / Accepted: 3 December 2014 / Published online: 17 December 2014

(C) Springer International Publishing Switzerland 2014

\begin{abstract}
Background and aims As part of a research consortium that explores ways to improve soil health, we study how entomopathogenic nematodes (EPNs) can be better exploited for the biological control of soil-dwelling insect pests in annual crops.

Methods We evaluated how tillage might affect belowground interactions in two 30-year running Swiss field trials by combining traditional (insect bait) and molecular (novel real-time qPCR protocols) methods. Soil samples (April and October 2013) were evaluated for the presence and activity of EPN soil food web assemblage comprising 13 EPN species, six nematophagous
\end{abstract}

Responsible Editor: Juha Mikola.

Electronic supplementary material The online version of this article (doi:10.1007/s11104-014-2358-4) contains supplementary material, which is available to authorized users.

R. Campos-Herrera $(\bowtie) \cdot$ G. Jaffuel $\cdot$ X. Chiriboga $\cdot$

R. Blanco-Pérez • T. C. J. Turlings

FARCE Laboratory, University of Neuchâtel,

Emile-Argand 11, Neuchâtel 2000, Switzerland

e-mail: raquel.campos@unine.ch

M. Fesselet · F. Mascher

Agroscope, Institut of Plant Production Sciences IPS,

Route de Duillier 50, CP 1012, 1260 Nyon, Switzerland

V. Půža

Laboratory of Entomopathogenic Nematodes, Institute of Entomology, Biology Centre, Czech Academy of Sciences, Branišovská 31, 37005 České Budějovice, Czech Republic fungi, one ectoparasitic bacterium, and the free-living nematodes (FLN) of the Acrobeloides group.

Results Mortality of sentinel larvae, as well as qPCR analyses (for which we provide seven new primers/ probes sets) found only trace levels of six EPN species, dominated by heterorhabditids species. Analysis of nematode progeny revealed that EPN compete intensely with FLN for insect cadavers. Overall, it appears that temperate annual cropping systems provide poor environments for EPN and that tillage does not negatively affect the natural occurrence of EPN.

Conclusions Natural occurrence of EPN in Swiss tillage soils was very low, and augmentation may be a promising strategy to improve the control of root pests of annual crops.

Keywords Entomopathogenic nematodes - Annual crops $\cdot$ Soil food web $\cdot$ Real-time qPCR $\cdot$ Galleria mellonella insect-bait

\section{Introduction}

Traditional agriculture employs numerous habitat modifications such as tillage, crop rotation, fertilization, and irrigation to enhance yield and promote crop protection against pests and diseases. The changes produced by those management practices affect the physical and chemical properties of soils and aim to enhance key abiotic factors (i.e., water and nutrient availability) for 
the crops. However, these modifications also alter the soil biota in ways that may eventually affect crop health (Campos-Herrera et al. 2014). Traditionally, agriculture has focused on the impact of soil organisms that are detrimental to the crop, but soils also contain beneficial organisms. Indeed, for modern sustainable agriculture, it is pertinent that naturally occurring organisms are used in ways that can improve crop health, optimize yields, and protect the environment from pollutants and disturbances. Understanding how the beneficial soil organisms interact in agro-ecosystems and how they are modulated by abiotic and biotic factors can provide new rational strategies to manage their presence in a sustainable manner.

Entomopathogenic nematodes (EPNs) belonging to the Steinernematidae and Heterorhabditidae families are considered among the most promising biological control agents to protect annual and perennial crops (Georgis et al. 2006; Kaya et al. 2006; Dolinski et al. 2012). EPNs can kill their insect hosts in less than $48 \mathrm{~h}$ thank to the concomitant action of mutualistic enteric $\gamma$ proteobacteria carried by the infective juvenile (IJ). The IJs actively search for a suitable host, and once located, the nematodes penetrate into the insect hemocoel and release the bacteria (Boemare 2002). The activity of both organisms results in the insect's death (Dillman et al. 2012; Sugar et al. 2012). Inside the cadaver, the EPN and bacteria reproduce in parallel resulting in several generations of EPN. When the resource is depleted, the nematode develops the IJ stage, which incorporate some of the bacteria and exit by the thousands into soil to start the cycle a new (Boemare 2002).

The efficacy of EPN as pest control agents depends on a number of environmental factors that include soil characteristics and agricultural management practices but also the interactions with other organisms in the soil (Duncan et al. 2007, 2013; Campos-Herrera et al. 2012). Numerous studies have advanced our understanding of EPN activity and efficacy linked to selected soil properties such as porosity or soil texture, $\mathrm{pH}$, and soil water potential (see review by Stuart et al. 2006). Yet, how the soil community modulates populations of EPN has received proportionally little attention, in part due to the methodological constrains linked to the study of soil organisms. These constraints have been greatly alleviated by the introduction of molecular techniques. Studies using traditional methods have already shown that populations of nematophagous mites, springtails, fungi, and other soil organisms can respond in a density-dependent manner to the exogenous application of EPN, resulting in a trophic cascade that reestablishes an equilibrium density as found for natural EPN communities (Jaffee and Strong 2005; Duncan et al. 2007; El-Borai et al. 2007; Ekmen et al. 2010; Greenwood et al. 2011; Ulug et al. 2014). Although most of these studies have focused on one group of natural enemies of EPN (i.e., microarthropods or fungi), these first studies underlined the critical impact of both environment and natural enemies on the EPN population dynamics.

PCR-based techniques have significantly evolved during the last decade and the current methods allow us to not only explore the diversity of organisms and their relationships but also their functions in ecosystems (Campos-Herrera et al. 2013a). Quantitative real-time PCR (qPCR) has been particularly successfully developed for belowground systems. The use of speciesspecific primers and probes enable the simultaneous identification and quantification of target species, even those cryptic organisms that were underestimated in the past or whose estimates were strongly dependent on the media used for culture (Campos-Herrera et al. 2011a; Pathak et al. 2012). At the moment, more than 20 realtime qPCR probes are available to study EPN assemblages along with bacterial and fungal antagonists and rselected, free-living nematode competitors in the field (Campos-Herrera et al. 2013a). The employment of this powerful tool recently revealed how new citrus management practices have altered the soil food web and the severity of a pest-disease complex (Campos-Herrera et al. 2014). Molecular analyses also showed that in the citrus system, the assemblage of EPNs in different soil habitats correlated with different patterns of herbivory and revealed interguild associations among different soil organisms (Campos-Herrera et al. 2012, 2013b, c). Combining molecular tools with traditional measurements of EPN activity by screening soil samples with insect-bait larvae can provide a comprehensive understanding of EPN activity and presence in agricultural soils and might lead to novel conservation or augmentation biological control strategies.

Annual crops such as maize and wheat are among the main cereals worldwide. A good understanding of how beneficial organisms promote health and improve the yields of these crops is of great interest. The planting of certain annual crops has already been shown to have a strong detrimental effect on natural populations of EPNs (Millar and Barbercheck 2002; Lawrence et al. 2006; 
Campos-Herrera et al. 2008). The very limited occurrence of EPN in these crops might be due to farmingrelated changes in soil properties, relatively high densities of natural enemies of EPN, limitations on the host availability, or a combination of these factors. The employment of new molecular tools might provide new insights into the relative importance of each factor as determinants of the natural occurrence of EPN and their natural enemies. Our hypothesis was that in frequently disturbed soils (high tillage), the natural occurrence and activity of EPN would be lower due to frequent exposure to harsh abiotic conditions and limited availability of insect hosts. These factors are expected to also negatively affect other members of the soil food web, such as nematodes that compete for insect cadavers, ectoparasitic bacteria that affect the IJs movement in the soil and nematophagous fungi, all of which have been shown as spatially associated and distributed with EPN in other systems (El-Borai et al. 2005; Campos-Herrera et al. 2012, 2013b; Pathak et al. 2012). Herein, our objectives were to (1) develop new molecular tools to evaluate EPN natural abundance in temperate soils, and (2) employ a combination of traditional measurements and those new molecular methods to explore the presence and activity of EPN under different agro-ecological scenarios in two 30-year-old Swiss field trials that are under different tillage regimes, and (3) evaluate the presence and activity of the natural enemies and direct competitors of EPN under different agricultural scenarios. Understanding the various factors that determine the dynamics in these soil agro-ecosystems will help in the development of new strategies for soil pest management. This work is conducted in the context of a Swiss research consortium (http://www.nfp68.ch/E) that explores ways to improve soil health, with the final goal to provide new tools for the enhancement of soil quality, pest control, and crop health.

\section{Materials and methods}

Field experiments, sampling methods, and nematode extraction

The natural occurrence of EPN and soil food web assemblages were evaluated in two 30-year running Swiss field trials, both located near Nyon, Switzerland $\left(46^{\circ} 24^{\prime}\right.$ $\mathrm{N}, 06^{\circ} 14^{\prime} \mathrm{E}, 430 \mathrm{~m}$ above sea level) and belonging to Agroscope, Institut des Sciences en Production
Végétale. The first experiment (plot 20 (P20)) compared (i) regular tillage $(20-25 \mathrm{~cm}$ depth $(\mathrm{T}))$ versus light tillage (10-15 cm (NT)) and (ii) monoculture (M) versus crop rotation $(\mathrm{C})$, following a randomized complete block design with four blocks. All plots $(18.5 \mathrm{~m} \times 8 \mathrm{~m})$ received three treatments with standard fertilizer and two treatments with herbicides (Azur 3.0 L/ha and Appel $0.8 \mathrm{~L} / \mathrm{ha}+$ Express max $35 \mathrm{~g} / \mathrm{ha}$ ). Soil characteristics averaged from samples at multiple locations were 22:48:30, sand/silt/clay; $\mathrm{pH} 8.1$; organic matter, $1.8 \%$. Winter wheat variety "Arina" was the crop in the monoculture treatments and maize variety "Ricardinio" in the crop rotation, with winter wheat "Arina" as the last crop in the previous season.

The second experiment (plot 29 (P29)) studied the effect of four levels of tillage, as follows: (i) standard tillage, $20-25 \mathrm{~cm}$ depth (T); (ii) light tillage, $12-15 \mathrm{~cm}$ (W15); (iii) minor tillage, 5-8 cm (W8); and (iv) direct planting (no till, SD). The experiment was placed in two soil types: CA (17:32:51, sand/silt/clay; $\mathrm{pH}$ 6.4; organic matter, $4.3 \%$ ) and CL (30:44:26, sand/silt/clay; pH 7.1; organic matter, $2.1 \%)$. The design was a randomized block design with three blocks for CA and four blocks for $\mathrm{CL}$ and was planted with winter wheat variety "Fiorina." Each plot $(8 \mathrm{~m} \times 4 \mathrm{~m})$ received standard fertilizer twice, one application of fungicide (Fandango $1.25 \mathrm{~L} / \mathrm{ha}$ ) and three herbicide treatments (Rundop $\max 2.0 \mathrm{~L} / \mathrm{ha}$, Azur $3.0 \mathrm{~L} / \mathrm{ha}$ and Appel $0.8 \mathrm{~L} / \mathrm{ha}+$ Express max $35 \mathrm{~g} / \mathrm{ha}$ ).

Soil samples were taken on 16th April and on 2nd October 2013 (total $n=88$ ). In the first sampling event, samples were composed of ten single soil cores $(10 \mathrm{~cm}$ diameter $\times 20 \mathrm{~cm}$ depth) collected in random locations within each plot, at least $1 \mathrm{~m}$ from the plot border. The ten samples per plot were well mixed, and a final sample ca. $3 \mathrm{~kg}$ per plot was reserved for further analysis. In the second sampling event, samples were collected from 20 single soil cores $(2.5 \mathrm{~cm}$ diameter $\times 20 \mathrm{~cm}$ depth $)$ following the same protocol as for the spring sampling, providing ca. $3 \mathrm{~kg}$ per plot. The samples were transported to the laboratory in coolers and kept at 4$5{ }^{\circ} \mathrm{C}$ until processed (within next $2-3$ days), ensuring a balance in the time of processing for all the treatments.

Each composite sample was gently mixed and nematodes were extracted from $500 \mathrm{~g}$ of fresh soil subsamples using the sucrose centrifugation flotation method (Jenkins 1964), in order to evaluate the EPN soil food web. Nematodes and other co-extracted organisms were settled in a 50-mL Falcon tube (Becton Dickinson 
Labware, USA) overnight at $4{ }^{\circ} \mathrm{C}$ and centrifuged during $10 \mathrm{~min}$ at $2860 \times \mathrm{g}$ to allow the aspiration of the excess water above the soil organisms deposited in the bottom. Thereafter, the pellet with the nematodes was placed in $1.5 \mathrm{~mL}$ Eppendorf tubes and stored at $-80{ }^{\circ} \mathrm{C}$ for DNA extraction procedures (Campos-Herrera et al. 2011b).

To evaluate EPN activity, two subsamples of $250 \mathrm{~g}$ of soil of each of the composed samples were baited with five Galleria mellonella L. (Lepidoptera: Pyralidae) larvae each. Larval mortality was assessed after 4 days incubation in the dark at $20-22{ }^{\circ} \mathrm{C}$. To confirm the results and also to allow nematodes to become active switching the "phased infectivity" (Griffin 2012), all samples were baited for a second time with five fresh larvae of G. mellonella (Hominick 2002). Cadavers were thoroughly rinsed with tap water, individually placed in White traps (White 1927) and were checked every 2-3 days to record nematode emergence. After 1 month of incubation, cadavers with no emergence or other obvious causes of death (i.e., bacterial, fungal infection) were dissected to check for penetration by nematodes that failed to reproduce. We took subsamples from all individual nematode-producing cadavers that were initially recovered from the soil and used them for (i) DNA analysis (original DNA from G. mellonella, OG), (ii) evaluation of activity by the recovered nematodes (Koch's postulates), and (iii) morphological identification of EPN and culturing, storing them at 10 $12{ }^{\circ} \mathrm{C}$. For the Koch's postulate evaluation, two 5.5$\mathrm{cm}$-diameter Petri dishes lined with filter paper were inoculated with a concentrated suspension of the individual isolates; four $G$. mellonella larvae were added per dish and were incubated in the dark at $20-22{ }^{\circ} \mathrm{C}$. Mortality was assessed twice per week. If nematodes emerged from this culture, an aliquot was saved for DNA analysis (Multiplication DNA, MG) and the rest were also maintained at $10-12{ }^{\circ} \mathrm{C}$ for further analysis. To control for false negatives, we repeated the Koch's postulate for all the original samples (OG) that did not produce nematode progeny.

Sources and culture of organisms

A total of 18 EPN species were used to develop and optimize molecular probes, which were used to identify and quantify the naturally occurring EPN in our field experiments (Table 1). Eight of these species have been previously reported for Swiss soils: Heterorhabditis bacteriophora Poinar (Rhabditida: Heterorhabditidae), Heterorhabditis megidis Poinar, Jackson \& Klein (Rhabditida: Heterorhabditidae), Steinernema affine (Bovien) Wouts, Mráček, Gerdin \& Bedding (Rhabditida: Steinernematidae), Steinernema bicornotum Tallosi, Peters \& Ehlers (Rhabditida. Steinernematidae), Steinernema carpocapsae (Weiser) Wouts, Mráček, Gerdin \& Bedding (Rhabditida: Steinernematidae), Steinernema feltiae (Filipjev) Wouts, Mráček, Gerdin \& Bedding (Rhabditida: Steinernematidae), Steinernema kraussei (Steiner) Travassos (Rhabditida: Steinernematidae), and Steinernema intermedium (Poinar) Mamiya (Rhabditida: Steinernematidae) (Steiner 1996; Kramer et al. 2001, Hominick 2002). Six additional species have been reported for Central European soils, as follows: Heterorhabditis zealandica Poinar (Rhabditida: Heterorhabditidae), Steinernema glaseri (Steiner) Wouts, Mráček, Gerdin \& Bedding (Rhabditida: Steinernematidae), Steinernema poinari Mráček Půža \& Nermut (Rhabditida. Steinernematidae), Steinernema weiseri Mráček, Stuarhan \& Reid (Rhabditida. Steinernematidae), Steinernema silvaticum Sturhan, Spiridonov \& Mráček (Rhabditida: Steinernematidae), and Steinernema sp. intermedium group (Hominick 2002; Kaya et al. 2006; Nguyen 2007; Mráček et al. 2014; Vladimir Půža, personal communication), and the four remaining species were included to evaluate cross-amplification and validate the new molecular tools. Morphological, morphometric, and molecular identifications were performed to confirm the identities of all the organisms used, with the exception of $S$. intermedium, for which we did not obtain living material. All other populations were cultured in G. mellonella larvae (Woodring and Kaya 1988) and stored in distilled water at $10-12{ }^{\circ} \mathrm{C}$. For $S$. intermedium, we used a plasmid with the completely published ITS region (AF171290) as positive control and quantification was established by DNA quantification as nanograms per microliter (Nguyen 2007; Campos-Herrera et al. 2011b).

We also investigated selected members of typical EPN soil food webs, comprising one free-living nematode, six nematophagous fungi and one ectoparasitic bacterium (Table 1). To evaluate the natural occurrence of Acrobeloides group which are free-living nematodes that might compete with EPN for the cadaver (CamposHerrera et al. 2012), we used a plasmid with the completely published ITS region (JQ237849) as 
Table 1 Species and sources of nematodes, fungi, and bacterium used in this study

\begin{tabular}{|c|c|c|c|c|}
\hline Type of organism/species & Population & Source & $\begin{array}{l}\text { Material used/unit of } \\
\text { measurements }\end{array}$ & $\begin{array}{l}\text { GenBank accession } \\
\text { number } \\
\text { ITS region }\end{array}$ \\
\hline
\end{tabular}

Nematodes: entomopathogenic nematodes

\begin{tabular}{|c|c|c|c|c|}
\hline Heterorhabditis bacteriophora & Commercial & Andermatt & Infective juvenile (IJs)/no. IJs & KJ93576 ${ }^{\mathrm{a}}$ \\
\hline Heterorhabditis indica & Btw & $\begin{array}{l}\text { L.W. Duncan and } \\
\text { F.E. El-Borai }\end{array}$ & Infective juvenile (IJs) & KJ938571 \\
\hline Heterorhabditis megidis & Commercial & Andermatt & Infective juvenile (IJs)/no. IJs & KJ938577 \\
\hline Heterorhabditis zealandica & Btw & $\begin{array}{l}\text { L.W. Duncan and } \\
\text { F.E. El-Borai }\end{array}$ & Infective juvenile (IJs)/no. IJs & GU174009 \\
\hline Steinernema affine & $\mathrm{CH}$ & Authors & Infective juvenile (IJs)/no. IJs & KJ938567 \\
\hline Steinernema bicornotum & D60 P1 & Authors & Infective juvenile (IJs)/no. IJs & KJ938568 ${ }^{\mathrm{a}}$ \\
\hline Steinernema carpocapsae & DOK-83 & Authors & Infective juvenile (IJs)/no. IJs & $\mathrm{KJ} 818295^{\mathrm{a}}$ \\
\hline Steinernema feltiae & RS-5 & Authors & Infective juvenile (IJs)/no. IJs & KJ938569 \\
\hline Steinernema glaseri & $\mathrm{NC}$ & D. Shapiro-Ilan & Infective juvenile (IJs)/no. IJs & GU173998 \\
\hline Steinernema intermedium & 82 from USA & Authors & $\begin{array}{l}\text { ITS rDNA sequence+ } \\
\text { pUC57/pg DNA }\end{array}$ & AF171290 \\
\hline $\begin{array}{l}\text { Steinernema sp. intermedium } \\
\text { group }\end{array}$ & VAD-1067 & Authors & Infective juvenile (IJs)/no. IJs & KJ696684 \\
\hline Steinernema kraussei & OS & Authors & Infective juvenile (IJs)/no. IJs & KJ696686 \\
\hline Steinernema poinari & 1160 & Authors & $\begin{array}{l}\text { ITS rDNA sequence }+ \\
\text { pUC57/pg DNA }\end{array}$ & KF241754 \\
\hline Steinernema riobrave & Btw & $\begin{array}{l}\text { L.W. Duncan and } \\
\text { F.E. El-Borai }\end{array}$ & Infective juvenile (IJs) & GU174000 \\
\hline Steinernema rarum & - & D. Shapiro-Ilan & Infective juvenile (IJs) & KJ938570 \\
\hline Steinernema silvaticum & IN30k3 & Authors & $\begin{array}{l}\text { ITS rDNA sequence+ } \\
\text { pUC57/pg DNA }\end{array}$ & KC631434 \\
\hline Steinernema weiseri & 1117 & Authors & Infective juvenile (IJs)/no. IJs & KJ696686 \\
\hline Steinernema sp. glaseri group & Arc & $\begin{array}{l}\text { L.W. Duncan and } \\
\text { F.E. El-Borai }\end{array}$ & Infective juvenile (IJs) & GU174002 \\
\hline \multicolumn{5}{|c|}{ Nematodes: free-living and competitor nematodes } \\
\hline Acrobeloides group & RT1-R15C & Authors (GenBank) & $\begin{array}{c}\text { 18S rDNA sequence+ } \\
\mathrm{pUC57/pg} \text { of DNA }\end{array}$ & JQ237849 \\
\hline \multicolumn{5}{|l|}{ Nematophagous fungi } \\
\hline Catenaria sp. & $1 \mathrm{D}$ & Authors & $\begin{array}{l}\text { ITS rDNA sequence }+ \\
\text { pUC57/pg of DNA }\end{array}$ & JN585805 \\
\hline Arthrobotrys dactyloides & H55 & L.W. Duncan and F.E. El-Borai & Pure culture/pg of DNA & KJ938574 \\
\hline Arthrobotrys musiformis & 11 & L.W. Duncan and F.E. El-Borai & Pure culture/pg of DNA & KJ938572 \\
\hline Arthrobotrys oligospora & 8 & L.W. Duncan and F.E. El-Borai & Pure culture/pg of DNA & KJ938573 \\
\hline Hirsutella rhossiliensis & 2931 & L.W. Duncan and F.E. El-Borai & Pure culture/pg of DNA & - \\
\hline Purpureocillium lilacinus & 9357 & L.W. Duncan and F.E. El-Borai & Pure culture/pg of DNA & KJ938575B ${ }^{\mathrm{a}}$ \\
\hline \multicolumn{5}{|l|}{ Ectoparasitic bacteria } \\
\hline Paenibacillus nematophilus & NEM2 & Authors (GenBank) & $\begin{array}{l}\text { 16S rDNA sequence of } 490 \\
\text { bp }+ \text { pUC57/copy numbers }\end{array}$ & AF480936 \\
\hline
\end{tabular}

${ }^{a}$ Sequences generated for this study

positive control. This nematode group is commonly encountered in agricultural soils (Liang et al. 2005). The nematophagous fungi Arthrobotrys dactyloides Drechsler (Heliotiales: Orbiliaceae), Arthrobotrys musiformis Drechsler (Heliotiales: Orbiliaceae), Arthrobotrys oligospora Fresen (Heliotiales: Orbiliaceae), Purpureocillium lilacinus (Thom) Luangsa-Ard, Houbraken, Hywel-Jones \& Samson 
(Hypocreales: Ophiocordycipitaceae), and Hirsutella rhossiliensis Pat (Hypocreales: Ophiocordycipitaceae) were maintained in pure cultures in Corn Meal Agar (Fluka analytical, Sigma-Aldrich, CO, USA), following the method described by Pathak et al. (2012), and morphological and molecular identifications were performed to confirm their identities (Pathak et al. 2012). The endoparasitic NF Catenaria sp. was analyzed by using a plasmid with the insertion of the full ITS region (JN585805), following the methods described by Campos-Herrera et al. (2014). The ectoparasitic bacterium Paenibacillus nematophilus Enright, Inerney \& Griffin (Bacillales: Paenibacilliaceae), which can attach in large numbers to the EPN cuticle, and hence impede nematode motility and host finding (Enright et al. 2003; Enright and Griffin 2004), was also assessed by using a plasmid with a 490-bp fragment of the 16S rDNA region insert reported for the strain P. nematophilus NEM2 (AY480936), transforming these values to copy numbers as described previously (Campos-Herrera et al. 2011a).

DNA extraction and molecular characterization of the ITS region

Before DNA extractions, all samples were mechanically disaggregated by using a sterile blue pestle assembled to a pellet mixer (VWR International, UK) for $15 \mathrm{~s}$. DNA from the nematodes emerged from insect cadavers isolated from the soil baits (OG) and their corresponding multiplication (MG) was extracted with the use of a QIAamp DNA mini kit (Qiagen ${ }^{\circledR}$ Ltd, Valencia, CA) following manufacturer's instructions. The DNA was recovered in $50 \mu \mathrm{L}$ of $\mathrm{mQ}$ water (Milli-Q Water System, Millipore S.A., Molsheim, France) and stored at $-20{ }^{\circ} \mathrm{C}$. DNA that was used for the standard curves, as well as DNA from the soil samples after sucrose centrifugation was extracted using the PowerSoil ${ }^{\mathrm{R}}$ DNA Isolation Kit (MoBio) (an improved version of the Ultra Clean Soil ${ }^{\mathrm{TM}}$ DNA kit, MoBio). DNA was recovered in a final volume of $60 \mu \mathrm{L}$ of the elution buffer. All the DNA extractions were twice analyzed for quality and quantity in a Nanodrop 1000 (control program ND-1000 v3.3.0, Thermo Scientific, Wilmington, DE). Aliquots of the original DNA were stored at $-80^{\circ} \mathrm{C}$ until analysis.

Molecular characterization of the ITS regions of the nematode and fungi that required a sequence for identification was performed by using primers and protocols described in Campos-Herrera et al. (2011b) for the nematode, and in Pathak et al. (2012) for the fungi (Table 1). All the DNA samples were diluted to a range between 0.5 and $1 \mathrm{ng} / \mu \mathrm{L}$ before conventional PCR protocols were applied. Amplifications were conducted using a Biometra T1 (Biolabo, France) with a $20-\mu \mathrm{L}$ final volume containing $1 \mu \mathrm{L}$ DNA template, $1 \times$ PCR buffer $\left(5 \times\right.$ ColorlessGoTaq ${ }^{\circledR}$ Reaction buffer, Promega), $200 \mathrm{nM}$ dNTP mix (Promega), and $400 \mathrm{nM}$ of each primer (Microsynth, Switzerland) with $0.68 \mathrm{U} \mathrm{GoTaq}^{\circledR}$ G2 DNA Polymerase (Promega). All runs contained a negative control by adding $\mathrm{mQ}$ water instead of DNA template. Aliquots of $4 \mu \mathrm{L}$ of each PCR product were mixed with GelRed nucleic acid stain (Biotium) and visualized after electrophoresis in $2 \%$ agarose gel in Tris-borate-EDTA (TBE; pH $8.0 \pm 0.1$ ), using the BenchTop 100 bp DNA ladder (Promega) to ensure PCR product size. Thereafter, individual bands were isolated, purified by QIAquick Gel Extraction $\left(\right.$ Qiagen $\left.{ }^{\circledR}\right)$, and cloned by using the pGEM ${ }^{\circledR}-T$ Easy Vector System I (Promega) kit. Transformation of the JM109 High-Efficiency Competent Cells (Promega) were performed by heat-shock following manufacturer's instructions. Cells were plated on LB agar supplemented with ampicillin and IPTG/X-Gal (ChromoMax $^{\mathrm{TM}}$, Fisher Scientific) and incubated at $37{ }^{\circ} \mathrm{C}$ overnight. Selected colonies were cultured overnight in LB supplemented with ampicillin, and the plasmid containing the insert was extracted with QIAprep Spin Miniprep (Qiagen ${ }^{\circledR}$ ), checking the occurrence of the expected insert in a TBE $0.8 \%$ agarose gel. DNA was sequenced at Macrogen (Macrogen Europe Laboratory, Inc). These sequences were aligned with the software Geneious (R.6.1.5., Biomatters, Inc.), compared with reported sequences using Blast (http://blast. ncbi.nlm.nih.gov) and submitted to GenBank.

Identification and quantification of target organisms by conventional and qPCR: design of species-specific primers and TaqMan probes, specificity,

and optimization

Species-specific primers and probe sets for the six NF, Acrobeloides group, and the EPN H. bacteriophora, $H$. zealandica, S. affine, S. carpocapsae, S. feltiae, $S$. glaseri, and $S$. kraussei have been reported in Atkins et al. (2005), Zhang et al. (2006), Torr et al. (2007), Campos-Herrera et al. (2011a, b, 2012), and Pathak et al. (2012). Additionally, we designed 
species-specific primers/probe for H. megidis, S. bicornotum, S. intermedium, Steinernema sp. intermedium group, S. poinari, S. silvaticum, and S. weiseri. Protocols for the design and optimization were those described by Campos-Herrera et al. (2011b). Briefly, sequences of the target nematode species and of closely related species were recovered from the NCBI database (http://www.ncbi.nlm.nih.gov/ Genbank/) in addition to the new populations sequenced in this study (Table 1). For each of the species, we performed multiple alignments of the close related sequences (Larkin et al. 2007) and selected areas of variability in the ITS region were selected to design the primers and probes using Primer-Blast (Rozen and Skaletsky 2000; http://www.ncbi.nlm.nih.gov/tools/ primer-blast/). Species-specific primers and TaqMan ${ }^{\circledR}$ probes for all the target organisms were synthesized by Microsynth, with all the probes labeled at the $5^{\prime}$ end with the fluorogenic reporter dye FAM and the $3^{\prime}$ end with the quencher BQH-1.

Standard curves for all the organisms for which pure cultures were available were prepared by extracting three independent aliquots by the Power Soil ${ }^{\mathrm{R}}$ DNA Isolation Kit (MoBio), combining these independent extractions to eliminate variation in DNA elution between samples (Torr et al. 2007; Campos-Herrera et al. 2011b). For EPN, aliquots of 300 IJs were prepared, and quantification was given as numbers of IJs. For the NF, we employed mycelia suspended in $\mathrm{mQ}$ water, and quantifications were established as picograms of DNA (Pathak et al. 2012). For the species for which we used plasmids as standards (Acrobeloides group, Catenaria sp., S. poinari, S. intermedium, and P. nematophilus), we synthesized selected sequences with the use of GenScript (USA Inc.), which were transformed in JM109 High-Efficiency Competent Cells as described before; therefore, quantifications are provided as picograms of DNA (Table 1) (Campos-Herrera et al. 2011a, 2012). DNA corresponding to $100 \mathrm{IJs}$ (EPNs), $1 \mathrm{ng} / \mu \mathrm{L}$ (NF), and $0.1 \mathrm{ng} / \mu \mathrm{L}$ (in the case of plasmid) were used in all the preliminary checks and optimization protocols.

Conventional PCR reactions were performed to evaluate the specificity of primers and their possible use for pure culture and multiplication identification (MG). We employed the same reaction conditions described for amplification above, with the cycling parameters for the species-specific primers used by Campos-Herrera et al. (2011b). The annealing temperature was optimized $(57,59,61,64$, and $66{ }^{\circ} \mathrm{C}$ ), and optimal temperature matched with the qPCR experiments.

Real-time PCR was performed in 100-well gene discs (Biolabo, Scientific Instruments, Switzerland) reaction plates on the Corbett Research real-time PCR. Before using TaqMan probes, the primers were tested using SYBR Green I (KAPA SYBR Green Fast qPCR kit universal master-mix), manufactured by Labgene (Switzerland). For all the studied organisms, we performed several tests to optimize reactions by primers concentrations $(250,300,400$, and $600 \mathrm{nM})$, probe concentration (100, 200, and $300 \mathrm{nM})$, and final volume $(20,15$, and $10 \mu \mathrm{L})$ by checking reactions dynamics at $66,64,61,59$, and $57^{\circ} \mathrm{C}$. In each run, $1 \mu \mathrm{L}$ of sample/ control was employed, with two technical repetitions per point. The negative control was established by adding $m Q$ water instead of DNA template, and positive controls were defined amounts of an organism, as described above. Thermal cycling was performed under the following conditions: $2 \mathrm{~min}$ at $60{ }^{\circ} \mathrm{C}$ and $5 \mathrm{~min}$ at $95^{\circ} \mathrm{C}$, followed by selected cycles of $95^{\circ} \mathrm{C}$ for $5 \mathrm{~s}$ and the adjusted temperature per organisms for $50 \mathrm{~s}$. We also varied the number of cycles for the new conditions for some of the organism, using 36 for the nematodes (EPN and FLNs), 50 for the NF, and 45 for the bacterium. In the studies from soil samples, nematodes were assessed from a tenfold dilution of the DNA; whereas, for the NF and ectoparasitic bacterium, we used the total DNA. A correction factor was derived from the dilution to transform qPCR data to original quantities. Linear regressions of $\log$ (quantities) and threshold cycle value $(\mathrm{Ct})$ were performed to derive standard curves for each organism $(P \leq 0.05)$.

Quantification of entomopathogenic nematodes in soil samples

Two experiments were conducted to evaluate suitability of the methods for the identification and quantification of EPN. Soil samples recovered at two different times from another field (plot 55) located at Agroscope (Nyon, Switzerland) were used to establish the soil community at this location. This was done in a similar manner as described by Campos-Herrera et al. (2011b). Soil characteristics averaged from samples at multiple locations were 55:26:19, sand/silt/clay; pH 7.8; organic matter, $2.8 \%$. In each of the experiments, soil samples were well mixed and aliquots of $250 \mathrm{~g}$ of fresh soil were extracted and processed by sucrose centrifugation as 
described above. In the first experiment, treatments included nematodes that were recovered from unaugmented soil (control) and nematodes extracted from soil augmented with 3, 10, and $100 \mathrm{IJs}(n=4)$ each of the following nematodes: S. carpocapsae, S. feltiae, $H$. megidis, and H. bacteriophora. The second experiment comprised three treatments, the un-augmented soil and the addition of three and ten IJs $(n=4)$ each of the following nematodes: S. affine, S. bicornotum, S. carpocapsae, S. feltiae, S. glaseri, Steinernema sp. intermedium group, S. kraussei, S. weiseri, $H$. bacteriophora, H. megidis, and H. zealandica. For DNA extraction, we used the PowerSoil ${ }^{\mathrm{R}}$ DNA Isolation Kit, and with real-time qPCR experiments, we assessed the quantity of each of the treatments for all the target nematodes. In all experiments, values obtained with qPCR assays were $\log (X+1)$ transformed before statistical analysis. One-sample $t$ tests $(P=0.05)$ were performed to compare the expected number of EPN in a sample with that measured by qPCR (SPSS 20.0).

Measuring entomopathogenic nematodes and related trophic guilds in tillage soil

Data from soil samples extracted with the sucrose centrifugation method provided information on the EPN soil food web assemblage at the two sampling times. The quantification of the EPN, FLN, NF, and bacterium were performed by qPCR assays as described before. Data were transformed prior analysis following Campos-Herrera et al. (2011a, b, 2012, 2014). NF parasitism of nematodes was estimated by dividing the DNA quantity of each NF species by the total amount of DNA in a sample as previously reported (CamposHerrera et al. 2012; Duncan et al. 2013). To estimate the total NF, we standardized the units of measurement among species $(0-1)$ by dividing all data within a species by the highest measurement for that species (Rooijvan et al. 1995). We estimated the species richness (number of species $(S)$ ) for all the treatments in both field experiments.

Data from $G$. mellonella baits were used for estimating the activity ( $\%$ larval mortality per plot, averaged by treatment) in each of the two field experiments and at both sampling times. Differences between total mortality (caused by any agent, i.e., nematode, bacteria, fungi, virus, etc.) and mortality caused by EPN were established. We combined Koch's postulate results and molecular analysis of the $\mathrm{OG}$ and $\mathrm{MG}$ data to gather information about the mortality agent per sample and plot in each treatment.

Data from activity (Galleria bait, assessed as success or fail, death or alive, respectively) was analyzed by a linear model fitted to a binomial or quasibinomial distribution ( $\mathrm{R}$ environment, R 3.0.2, CRAN 2014). The rest of the variables (quantitative) were analyzed through linear model following a stepwise procedure where not normally distributed data were corrected using a rank transformation (package GenABEL, R 3.0.2, CRAN 2014). In the first experiment (P20), factors were (i) tillage (regular versus light), (ii) culture (monoculture versus crop rotation), and (iii) sampling time (spring versus autumn); in the second experiment (P29), the treatments were: (i) tillage (four levels), (ii) soil type (CA and CL), and (iii) sampling time (spring versus autumn). Pearson's correlation coefficient $(r)$ was used to measure the strength of relationships between selected organisms in each of the experiments and sampling time (SPSS 21.0). All data are presented as mean \pm SEM of untransformed values.

\section{Results}

Identification and quantification of target organisms by conventional and real-time qPCR

All the new sequences generated for the target species were in agreement with the expected species identification (GenBank accession number referred in Table 1). Seven sets of primers and probes for EPN were developed in this study (Table 2), and we used an additional eight primer/probe combinations from previous reports (Torr et al. 2007; Campos-Herrera et al. 2011a, b, 2012). Most of the primers amplified only the target species (Supplementary S-Table 1), with some exceptions that produced less intense bands for other species, most of them almost undetectable. Using conventional PCR, we found that the primers reported by Torr et al. (2007) for S. kraussei also amplified S. affine, S. feltiae, $S$. silvaticum, and $S$. weiseri, whereas the primers for $S$. silvaticum limited the cross-amplification to S. kraussei and slightly to $S$. affine. When the primers were tested using SYBR Green fluorescence in qPCR experiments, we found unspecific amplifications for some species, most of them in agreement with the bands observed in conventional PCR (Supplementary S- 
Table 2 Specific primers and TaqMan ${ }^{\circledR}$ probes for detecting seven species of entomopathogenic nematodes and characteristic PCR product size

\begin{tabular}{|c|c|c|}
\hline Species & Primers and probe $\left(5^{\prime}-3^{\prime}\right)$ & PCR product size (bp) \\
\hline \multirow[t]{3}{*}{ Heterorhabditis megidis } & F: GCAATGTCGAGTGTCGAACG & \multirow[t]{3}{*}{132} \\
\hline & R: CGCTACACATCCACAGGTACA & \\
\hline & P: FAM-TCCGAATATTGGCAACATGTC-BHQ-1 & \\
\hline \multirow[t]{3}{*}{ Steinernema bicornotum } & F: ACGGAGCAGCTGTATGATCG & \multirow[t]{3}{*}{91} \\
\hline & R: CGAGTCACTGAACCGACCTC & \\
\hline & P: FAM-GCTGTGGTGATATATGCTTGACATTGC-BHQ-1 & \\
\hline \multirow[t]{3}{*}{ Steinernema intermedium } & F: GGTTTAGATTTGTTTACGCTTCTCA & \multirow[t]{3}{*}{99} \\
\hline & R: CTCACAGAGCATAACAACGCA & \\
\hline & P: FAM-TCACTTCTAGTGAATGTGCGAATTGCT-BHQ-1 & \\
\hline \multirow[t]{3}{*}{ Steinernema sp. intermedium group } & F: ATTGCTTCTAATATGAGTTGGTTGT & \multirow[t]{3}{*}{132} \\
\hline & R: GCCTTGCTTGAGTTGAGGTC & \\
\hline & P: FAM-TGAATGTGCGAATTGCTGTGCGA-BHQ-1 & \\
\hline \multirow[t]{3}{*}{ Steinernema kraussei-silvaticum group } & F: TCTGCTGTTTGTTTCGAAGCGA & \multirow[t]{3}{*}{103} \\
\hline & R: TGTCCATCACCACAGTCACG & \\
\hline & P: FAM-ACGGCTACGAAGGGTTTCTGTAGGT-BHQ-1 & \\
\hline \multirow[t]{3}{*}{ Steinernema poinari } & F: TGCTTCTAATGTGAGTTGGCTGT & \multirow[t]{3}{*}{85} \\
\hline & R: ACTCACAGAGCATAATAGTGCAT & \\
\hline & P: FAM-CGCTTCTAGTGAATGTGTGAATTGCC-BHQ-1 & \\
\hline \multirow[t]{3}{*}{ Steinernema weiseri } & F: TTTCAAAATGTCAGCGGCCC & \multirow[t]{3}{*}{123} \\
\hline & R: TCAGCGGGTAATCTTGCTTGA & \\
\hline & P: FAM-TCGACACAACACGACTCGTTTGT-BHQ-1 & \\
\hline
\end{tabular}

Code: $F$ forward primer, $R$ reverse primer, $P$ TaqMan ${ }^{\circledR}$ Probe

Table 2). In several cases, the amplifications showed a different melting temperature $(\mathrm{Tm})$ (Supplementary STable 3), which can be useful for assessing the EPN species differences, if required.

Using TaqMan probes in the qPCR assays significantly improved the specificity. With some exceptions, we only detected the target species (Supplementary S-Table 4). In some cases, we observed a late amplification with a low likelihood of detecting the nontarget species with this primer/probe combination, as reported for other systems (Campos-Herrera et al. 2011a). For example, when we employed primers/probes for $H$. zealandica, we observed amplification after cycle 30 with DNA from 100 IJs of $H$. indica, and hence, the probability of cross-detection is very low. However, in the case of the primers/probe designed for S. kraussei by Torr et al. (2007), we observed that the species $S$. affine, S. feltiae, S. silvaticum, and $S$. weiseri amplified with different degree of specificity. By using these primers/probe, the amplifications observed for $S$. feltiae and $S$. affine might be considered unlikely (late cycles), whereas the amplifications observed for S. weiseri and especially S. silvaticum (cycles 25.7 and
14.8, respectively), make it highly probable that they cannot be distinguished. This problem of crossamplification was significantly reduced when using the primers/probe set designed for S. silvaticum. In this case, only the species $S$. affine (after cycle 34 ) and S. kraussei (cycle 20) provided amplification. As noted before, the cross-amplification with $S$. affine seems very unlikely (at the end of the cycles), but when used with $S$. kraussei DNA, there was almost no difference with the amplification dynamics observed with the primers/probe reported by Torr et al. (2007). Hence, the primers/probe described herein for $S$. silvaticum can be readily used to detected S. kraussei. This new primers/probe set provided enough resolution to successfully distinguish both closely related S. kraussei and S. silvaticum (Sturhan et al. 2005; Mráček et al. 2014) from the other species we tested, providing the identification of $S$. kraussei-silvaticum group. We therefore employed this new primers/probe in combination with the standard curve for S. kraussei. All the primers/ probe combinations provided a linear relationship between the $\mathrm{Ct}$ values and log-transformed EPN data once reactions were optimized (Supplementary S-Table 5). The 
qPCR reactions for the other members of the soil food web were also optimized (Supplementary S-Table 5).

Entomopathogenic nematode quantification in soil samples

Only trace levels of the nematodes $H$. bacteriophora and $H$. megidis were found in the control (unaugmented) samples in both experiments (two samples in each one) with values $<1 \mathrm{IJs} /$ sample, so these were not considered for further analysis (data not shown). We observed very few minor deviations in the numbers provided by qPCR experiments and the expected quantity. In both experiments, none of the tested nematodes showed a significant increase or decrease in the value when augmented with three IJs (Fig. 1). In the first experiment, when we augmented with ten IJs, only for $H$. bacteriophora we detected slightly higher numbers than expected ( $13.2 \mathrm{IJ} ; t_{3}=3.333, P=0.045$ ), and in the case of augmentation with $100 \mathrm{IJs}$, two of the species gave higher numbers $\left(S\right.$. feltiae, $111.9 \mathrm{IJs}, t_{3}=12.785$,
$P=0.001 ; S$. carpocapsae, $116.9 \mathrm{IJs}, t_{3}=5.511, P=$ 0.012) (Fig. 1a). In the second experiment, when we augmented with ten IJs, only 3 out of 12 primers/probes significantly overestimated the expected quantities ( $S$. carpocapsae, $t_{3}=4.162 ; P=0.025 ; S$. silvaticum, $t_{3}=3.097, P=0.053 ; H$. bacteriophora,$t_{3}=3.917 ; P=$ 0.030) (Fig. 1b). However, none of these amplifications exceeded the range already reported in previous studies (Campos-Herrera et al. 2011a, b), and we consider therefore that the primers/probe provide quantification with the same degree of accuracy for this new system.

Entomopathogenic nematode soil food web assemblage in tillage soil

Six of the 13 targeted EPN species were detected at field sites P20 and P29: S. affine, S. carpocapsae, S. feltiae, S. kraussei-silvaticum, H. bacteriophora, and H. megidis. S. kraussei-silvaticum, H. megidis, and $H$. bacteriophora were encountered at both field sites, although the last one was only detected in October 2013.


Fig. 1 Estimation of the number of infective juveniles (IJs) in soil samples using qPCR experiments. a Augmentation experiment with 3, 10, and 100 IJs of Heterorhabditis bacteriophora $(\mathrm{Hb})$, Heterorhabditis megidis (Hm), Steinernema feltiae (Sf), and Steinernema carpocapsae ( $\mathrm{Sca}$ ). b Detection of three and ten IJs of $S$. feltiae (Sf), S. carpocapsae (Sca), Steinernema glaseri $(S g)$, Steinernema bicornutum (Sbic), Steinernema sp. intermedium group (Sint-g), Steinernema affine (Saff), Steinernema weiseri (Swei), Stinernema kraussei (Sk), S. kraussei with Steinernema silvaticum primers/probe (Ssilv), Heterorhabditis zealandica $(\mathrm{Hz})$, $H$. bacteriophora $(\mathrm{Hb})$, and $H$. megidis $(\mathrm{Hm}) .{ }^{*} P<0.05$, values significantly different than expected in one sample $t$ test. Data are shown as means \pm SEM 
Of the other three species, S. feltiae was only detected in two plots (C-T and C-NT) in P20, whereas S. carpocapsae (one plot (T)) and $S$. affine (one plot (W8)) were detected in P29, only once in October 2013. The EPN community was dominated by Heterorhabditis spp. at both sites, with $H$. megidis most prevalent in spring and a shift to H. bacteriophora in autumn (Fig. 2a).

Because most of the values per EPN species recorded in the plots were on average below $1 \mathrm{IJs} / 100 \mathrm{~g}$ dry soil, we combined and analyzed the data to represent EPN abundance per treatment. EPN as a group was not affected by tillage, crop rotation (P20), or by soil type (P29) (Table 3), although slightly higher numbers were obtained in monoculture plots (P20) and CA soil (P29) (data not shown). In general, EPNs were more numerous in autumn than in spring in both fields, (Table 3; Fig. 2a, $P<0.01)$. Similarly, EPN richness was higher in autumn in both plots (Table $3, P<0.01$ ), with one versus three species in P20 and two versus five in autumn (Fig. 2a).

Several natural enemies of EPNs were detected at both sites. The NF P. lilacinus, $H$. rhossiliensis, and A. oligospora were detected during both sampling periods; Catenaria sp. was also present at both sites, with the exception of $\mathrm{P} 20$ during October 2013. A. musiformis and $A$. dactyloides were never detected in the samples. In addition to the NF, free-living nematodes of the Acrobeloides group were detected in all treatment types and at both sampling periods in P20 and P29. However, the ectoparasitic bacterium $P$. nematophilus was not detected in any sample.

Similarly to the EPN, we subjected the total NF to further analyses. NF quantities were slightly higher in autumn (Fig. 2b), but this difference was not significant (Table 3). Only the higher richness detected in autumn as compared with spring in P29 was significant (Table 3, $P<0.01)$. NF richness was also higher in plots under crop rotation (P20, Fig. 3a; Table 3, $P<0.05$ ), and the total NF infection rate was higher in CA soils (P29, Fig. 3c; Table 3, $P<0.001)$. The nematodes in the Acrobeloides group were detected at both sites and in all the treatments and both sampling periods, with higher numbers in P20 and with a significant higher occurrence in spring (Table 3; Fig. 2c, $P<0.01$ ). The DNA of these nematodes was also detected in larger quantities in the monoculture treatment (P20, Fig. 3b; Table 3, $P<0.01$ ) and in CA soil (P29, Fig. 3d; Table 3, $P<0.001)$. Acrobeloides nematodes were reduced in the
Entomopathogenic nematodes


c Free-living nematodes, cadaver competitor

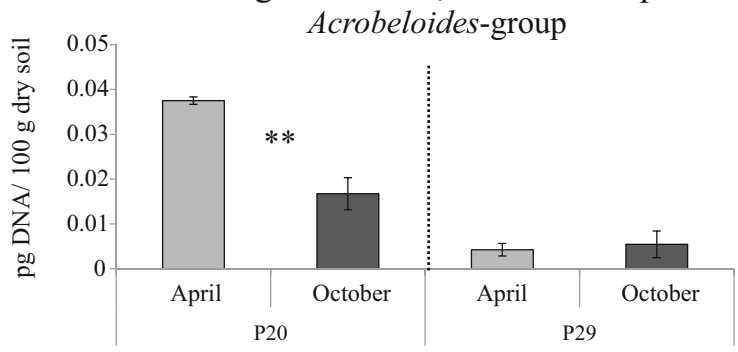

Fig. 2 Entomopathogenic nematodes (EPNs) natural occurrence along with selected members of their soil food web: nematophagous fungi (NF) and free-living nematodes (FLNs). Data represent the average value of the combined species-specific quantification of each of the organisms in two field trials (P20 and P29) at two different sampling points in 2013. a Total number of EPN infective juveniles (IJs) of the species $S$. feltiae (Sf), $S$. carpocapsae (Sca), S. kraussei-silvaticum (Sk-s), S. affine (Saff), Heterorhabditis bacteriophora $(\mathrm{Hb})$, and $\mathrm{H}$. megidis $(\mathrm{Hm})$. The dominance of the EPN community is represented by the corresponding proportion (pie graph above each column). b Total NF infection rate (IR) proportion for the species Purpureocillium lilacinus (Plil), Catenaria sp. (Cat), Hirsutella rhossiliensis (Hrhos), and Arthrobotrys oligospora $(A o)$. The dominance of the NF community is represented by the corresponding proportion (pie graph above each column). c Occurrence of the FLNs Acrobeloides group DNA quantities. Data are shown as means \pm SEM

deepest tillage treatment. This was only marginally significant in P20 ( $P=0.067$, data not shown) but significant in P29 (Table 3; Fig. 4, $P<0.05$ ). 
Table 3 Statistical analysis of the natural occurrence of the organisms (in $100 \mathrm{~g}$ of dry soil) detected by qPCR in the soils from the two field experiments (P20 and P29) and the ecological indices

\begin{tabular}{|c|c|c|c|c|c|c|c|}
\hline $\mathrm{P} 20$ & Tillage (T) & Crop rotation $(\mathrm{CR})$ & Period $(\mathrm{P})$ & $\mathrm{T} * \mathrm{CR}$ & $\mathrm{CR} * \mathrm{P}$ & $\mathrm{T} * \mathrm{P}$ & $\mathrm{T} * \mathrm{CR} * \mathrm{P}$ \\
\hline \multicolumn{8}{|l|}{ Entomopathogenic nematodes } \\
\hline Total IJs & n.s. & n.s. & $37.9_{31} * * *$ & n.s. & n.s. & n.s. & n.s. \\
\hline Richness & n.s. & n.s. & $26.1_{31} * * *$ & n.s. & n.s. & n.s. & n.s. \\
\hline \multicolumn{8}{|l|}{ Nematophagous fungi } \\
\hline Total IR & n.s. & n.s. & n.s. & n.s. & n.s. & n.s. & n.s. \\
\hline Richness & n.s. & $5.870_{31} *$ & n.s. & n.s. & n.s. & n.s. & n.s. \\
\hline \multicolumn{8}{|l|}{ Free-living nematodes } \\
\hline Acrobeloides group ng DNA & n.s. & $12.560_{30} * *$ & $9.370_{30} * *$ & n.s. & n.s. & n.s. & n.s. \\
\hline P29 & Tillage (T) & Soil type (S) & $\mathrm{T} * \mathrm{~S}$ & $\mathrm{~T} * \mathrm{P}$ & & & \\
\hline \multicolumn{8}{|l|}{ Entomopathogenic nematodes } \\
\hline Total IJs & n.s. & n.s. & $2.631_{52} * *$ & n.s. & n.s. & n.s. & n.s. \\
\hline Richness & n.s. & n.s. & $3.403_{52} * *$ & n.s. & n.s. & n.s. & n.s. \\
\hline \multicolumn{8}{|l|}{ Nematophagous fungi } \\
\hline Total IR & n.s. & $48.077_{55} * * *$ & n.s. & n.s. & n.s. & n.s. & n.s. \\
\hline Richness & n.s. & n.s. & $3.403_{52} * *$ & n.s. & n.s. & n.s. & n.s. \\
\hline \multicolumn{8}{|l|}{ Free-living nematodes } \\
\hline Acrobeloides group ng DNA & $3.969_{54} *$ & $62.071_{52} * * *$ & n.s. & n.s. & n.s. & n.s. & n.s. \\
\hline
\end{tabular}

Data are presented as $F_{d f}$

$I R$ infection rate for the nematophagous fungi (NF), equivalent to picograms NF DNA/total DNA, n.s. not significant

$* P<0.05 ; * * P<0.01 ; * * * P<0.001$, probability levels

Entomopathogenic nematode and related trophic guilds activity in tillage soil

The percentage mortality of G. mellonella larvae was used as proxy for the suppressive effects of the soils in the different treatments. Overall, mortality (caused by any factor) was lower than $15 \%$ in both experiments, and a significant difference was only observed between the two sampling times $(P<0.05)$, with higher mortalities recorded in spring (data not shown). The larval mortality caused by EPN activity was below $4 \%$ in all of the treatments and sampling times. Yet, despite these low levels, EPN activity was found to be significantly higher in monoculture $(3.8 \% \pm 1.1)$ than in crop rotation $(1.1 \% \pm 0.7$; P20, $P=0.013)$.

Morphological characterization and molecular analyses (sequencing and real-time qPCR) on the OG samples (nematodes recovered from the original cadaver) revealed that $79 \%$ of the nematode-containing cadavers in P20 and $78 \%$ in P29 had a mix of EPN with the competing Acrobeloides group and/or member of the
Oscheius genus (selected sequences submitted to GenBank, accession numbers: KJ938578-KJ938590). The rest of the cadavers with nematodes contained only these free-living nematodes. The two EPN species recovered from the cadavers, H. megidis and S. krausseisilvaticum, were also detected in the soil samples by qPCR in both field sites. Some cadavers produced even a mix of two species of EPN (11\% in P20 and $33 \%$ $\mathrm{P} 29)$. In $\mathrm{P} 20$, all the cadavers produced a mix of $H$. megidis with any of the two free-living nematodes, with $50 \%$ of the cases containing both Acrobeloides group and Oscheius spp. Two cadavers even contained S. kraussei-silvaticum with $H$. megidis, as well as the two free-living nematodes groups. In P29, we found four nematodes ( $S$. kraussei-silvaticum, $H$. bacteriophora, Acrobeloides group, and Oscheius spp.) in three individual cadavers, whereas the rest of the EPN-containing cadavers had a mix of $H$. megidis and Oscheius spp. Less than $35 \%$ of the nematodes that emerged from the original cadavers could produce new generations when offered fresh G. mellonella larvae 
Nematophagous fungi

\section{a}

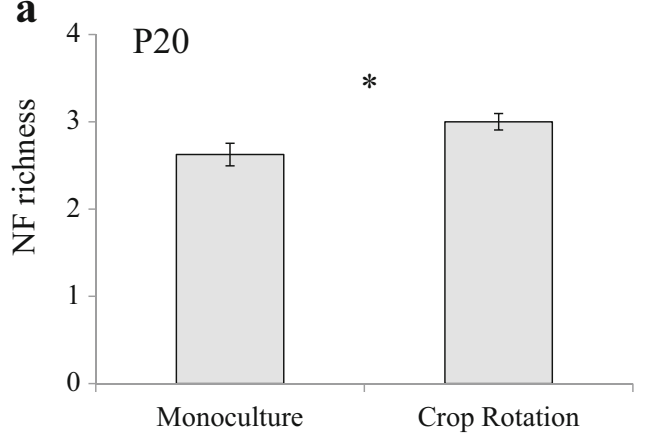

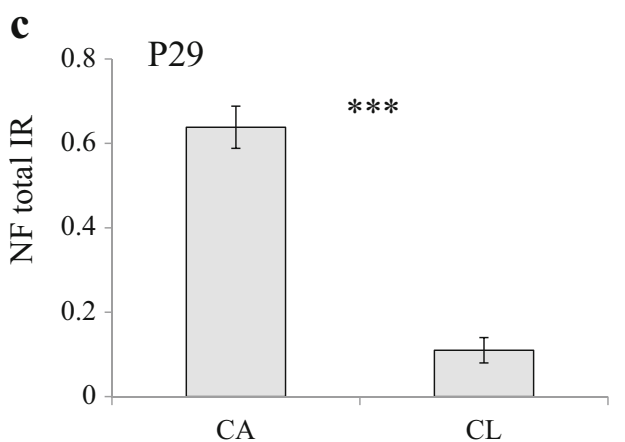

Free-living nematodes, cadaver competitors



Fig. 3 Natural occurrence of the entomopathogenic nematodes natural enemies in the treatments "monoculture" and "crop rotation" in the field experiment P20 and in plots with high clay content $(C A)$ and high silt content $(C L)$ in the trial P29. a Nematophagous fungi $(\mathrm{NF})$ richness and $\mathbf{b}$ presence of free-

(MG samples). In the next-generation EPN-infected larvae, we found the co-occurrence of EPN and Oscheius spp.



living nematodes (FLNs) from the Acrobeloides group in "monoculture" versus "crop rotation" treatments. $\mathbf{c} N F$ total infection rate (IR) and $\mathbf{d}$ FLNs presence in two soil types. $* P<0.05 ; * * P<0.01$; $* * * P<0.001$, values significantly different after stepwise model of the transformed variables. Data are shown as means \pm SEM

The analysis of correlations among different guilds (EPN, NF and Acrobeloides group) and EPN-caused mortality showed a positive correlation between EPN
Fig. 4 Natural occurrence of the FLNs Acrobeloides group DNA quantities in a gradient of tillage in the field experiment P29: (i) standard tillage $20-25 \mathrm{~cm}$ depth (T), (ii) light tillage $12-15 \mathrm{~cm}$ (W15), (iii) minor tillage $5-8 \mathrm{~cm}$ (W8), and (iv) direct planting (no till, SD). Data are shown as means $\pm \mathrm{SEM}$

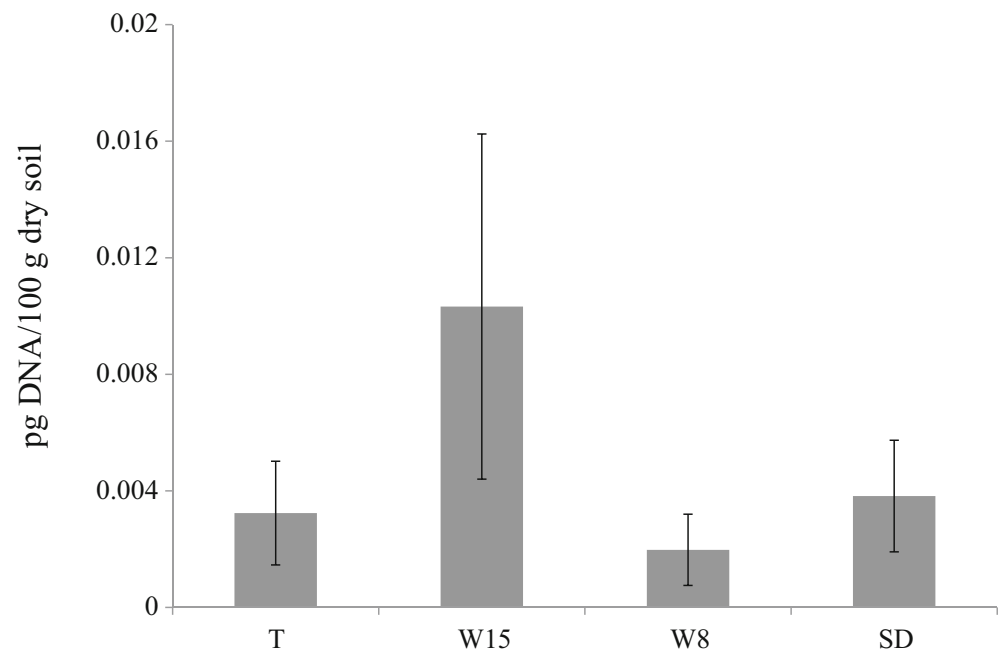


activity and free-living nematodes Acrobeloides group in P20 ( $r=0.506, P=0.012)$. Moreover, in P29 we observed a positive correlation between total NF occurrence with Acrobeloides group $(r=0.442, P=0.001)$. There was also a marginal positive correlation between total NF and total EPN $(r=0.248, P=0.066)$.

\section{Discussion}

We successfully developed seven species-specific primers and probes for EPN species that naturally occur in Central Europe and demonstrated that the previously described qPCR protocols for the study of EPN soil food webs (Campos-Herrera et al. 2011a, 2012; Pathak et al. 2012) can be readily employed to investigate similar ecological scenarios in annual crops. We combined traditional and molecular tools to investigate the natural occurrence of EPN and several of their natural enemies in cereal crops in Swiss field trials. While integrating the new molecular tools with the previous qPCR protocols, we realized that empirical optimization and reevaluation were critical to achieve reliable quantification. In the present study, several changes were made to adjust the reaction times and available equipment, which was different from previously used qPCR protocols (Torr et al. 2007; Campos-Herrera et al. 2011a, b, 2012; Pathak et al. 2012). Overall, conventional PCR detected several cross-amplifications, which persisted when using SYBR Green chemistry. However, the third level of specificity provided by TaqMan probes mostly resolved these cross-amplifications. These changes allowed the detection of accurate numbers of IJs, similarly to previous quantification experiments (CamposHerrera et al. 2011a, b).

Some differences were found for cross-amplification with previously tested primers/probe. For example, Campos-Herrera et al. (2011b) did not record any cross-amplification between the species-specific primers and probes designed for $H$. zealandica and the nontarget species $H$. indica. The new conditions showed a signal for $100 \mathrm{H}$. indica $\mathrm{IJ}$ after cycle 30 . Although it was unexpected, the likelihood of detecting the nontarget species with this primer/probe combination under the conditions used is very low, since it would require quantities of DNA 3 orders of magnitude higher (Campos-Herrera et al. 2011a). Another difference was encountered for $H$. bacteriophora for which annealing temperature was reported as $59{ }^{\circ} \mathrm{C}$ (Campos-Herrera et al. 2011a). The new protocols required a significant increment to $64{ }^{\circ} \mathrm{C}$ to avoid cross-amplifications with H. megidis. Similarly, the detection of the ectoparasitic bacterium $P$. nematophilus required also $64{ }^{\circ} \mathrm{C}$ to avoid primer-dimer formation. However, the most challenging case was the detection of $S$. kraussei and S. silvaticum. Firstly, we employed the primers/probe designed by Torr et al. (2007), who showed no cross-amplification with $S$. feltiae, nor with $S$. affine when using its corresponding TaqMan probe. However, under our conditions, this primers/probe combination not only gave cross-amplification with these two species but also with two new species tested herein: $S$. weiseri and S. silvaticum. Although the amplification of the two first species seems unlikely, because their amplifications were at the later cycles $(>32)$, the two newly tested species amplified in the cycles 25 and 14, respectively, and hence, significantly increased the possibility of cross-amplification, even when these primers/probe sets were tested at $64{ }^{\circ} \mathrm{C}$ as annealing temperature and the lowest concentrations of primers and probe. Our new primers/probe combinations significantly improved the analyses, by avoiding cross-amplification with $S$. feltiae and $S$. weiseri, and a late signal after the cycle 34 with S. affine. However, our primers/probe did amplify S. kraussei and S. silvaticum, sister taxa as observed in the recent analysis by Mráček et al. (2014). The minimal differences on the available ITS sequences for both species (sharing $98 \%$ similarity) were not enough to allow the design of suitable primers/probe combination for the use with qPCR protocols. The new molecular set is interchangeable to detect either S. kraussei or S. silvaticum, and therefore, it was possible to quantify these nematodes by using the standard curve constructed with IJs of $S$. kraussei in combination with the S. silvaticum primer/probe, resulting in the defined detection of the S. kraussei-silvaticum group. Both species are found in Europe and have been reported to co-occur in sites in Germany and Sweden (Nguyen et al. 2007). In Switzerland, two previous studies on EPN distribution reported the presence of S. kraussei (Steiner 1996; Kramer et al. 2001), but both studies were performed before the formal description of $S$. silvaticum by Sturhan et al. (2005), leaving open the possibility that these closely related species were not initially distinguished. Other countries from central Europe have records on S. silvaticum such as Belgium, Czech Republic, and the Netherlands (Nguyen 2007). Differences in habitat or host preference might allow 
the sympatric distribution of the sister species, although both have been encountered associated to forest, grassland and cultivated lands (Hominick 2002; Nguyen 2007). Therefore, it remains possible that we detected one of the two species, or a combination of the two. Further studies are needed to increase the resolution to distinguish between these two sister taxa, in order to ensure detection and quantifications of each of the two species separately.

Six of the eight EPN species previously detected in Swiss soils were encountered in our agricultural samples: H. megidis, H. bacteriophora, S. feltiae, S. carpocapsae, S. affine, and S. kraussei-silvaticum (Steiner 1996; Kramer et al. 2001). None of the other seven EPN species for which we tested species-specific primers and probes were detected in the samples. However, ongoing research has revealed the occurrence of some of these other species associated with different Swiss habitats such as forest and grassland (i.e., S. poinari and Steinernema sp. intermedium group) (unpublished data). Heterorhabditis spp. were the dominant species in all plots. These results contrast with the previous field studies in which steinernematids were the dominant species (Steiner 1996; Kramer et al. 2001). This could simply be because the studies were conducted in totally different areas and habitats, using different methodologies and at different scales. Another explanation could be linked to the life cycle of the heterorhabditids nematodes. The trace quantities detected in our soil samples suggest unfavorable conditions and low host densities. Contrary to most of the amphimictic steinernematids species (Griffin et al. 2001; Adams and Nguyen 2002), heterorhabditids develop hermaphrodites as the first generation of adults, and hence, only one IJ is needed to produce new progeny (Adams and Nguyen 2002). This mode of reproduction may be favored in the sampled habitats. Differences due to the methodology seem unlikely since the same type of insect bait was used in all the cases, complemented with comparable qPCR analyses of the soil food web. Finally, by surveying in April and October 2013 we gained insight about temporal dynamics that may lead to differences in EPN occurrence. More EPN were encountered in October than in April, but at both time points heterorhabditids were the dominant species, even though we observed a clear shift in species composition. Further studies are required to confirm these seasonal differences.

The fact that we detected only trace quantities of EPN might be attributed to an overall intense management of the soils in annual crops, including the use of agrochemicals that might have even stronger effects than the tillage levels in both field trials. Previous studies reported almost no EPN activity in annual crops under either organic or conventional management (Lawrence et al. 2006; Campos-Herrera et al. 2008). The management practices may affect soil properties in ways that do not support EPN populations, for example, by exposing them to ultraviolet radiation or limited water availability (Stuart et al. 2006). Also, these changes can alter the soil biota resulting in a detrimental effect on the EPN native populations. For example, recent studies have shown how considerable changes in the soil physical-chemical properties promoted by a new citriculture program in Florida citrus groves affect the soil food web in ways that potentially reduce the presence of steinernematids (Campos-Herrera et al. 2013c, 2014). Management in annual crops might also reduce the numbers of suitable hosts for EPN. Indeed, natural and perennial systems have been shown to provide more consistent conditions for the settlement and persistence of these nematodes by supporting a stable rhizosphere community (CamposHerrera et al. 2007, 2008). Similar studies using qPCR in Florida citrus groves detected higher numbers of native EPNs than the trace levels observed in the annual crops under study in Swiss soils (Campos-Herrera et al. 2013b, c, 2014). Despite the obvious climatic and soil properties differences between these two areas, ongoing studies characterizing EPN soil food web from Swiss soils from different habitats have also revealed considerably higher numbers than those in agricultural soils, in some ways similar to these observed in Florida (unpublished data). These observations confirm the notion that the annual crops provide unfavorable habitats for EPN development and should prompt efforts to develop novel management strategies to favor EPN.

In addition to the soil environment and the host availability, the presence and dynamics of the natural enemies of the EPN might play an important role in their persistence. We investigated the natural occurrence of several NF, one ectoparasitic bacterium, and one group of FLN with the EPN. In our samples, the ectoparasitic bacterium $P$. nematophilus was not detected, whereas the other two guilds were widespread in both field trials. NF are commonly encountered in agricultural soils (Gray 1988), and their numbers and richness can be species dependent (Jaffee et al. 1998). In agreement with the studies by Persmark et al. (1996), also in agricultural soils, the numbers of NF in both field experiments 
tended to be higher and richer in autumn, possibly due to changes in soil humidity, temperature or food availability, among other plausible reasons. In addition to this, NF richness was higher in the plots under crop rotation (P20) and plots with heavy soils or high levels of organic matter (P29). These observations might be linked with the availability of water in these soils, an important factor for NF distribution, particularly in the zoosporic fungi (Freeman et al. 2009). Maize was the crop in the rotation, which might provide higher cover and protection from desiccation than the wheat. Similarly, soils with high clay content might hold water for longer periods than those with more sand and silt. On the other hand, the FLNs Acrobeloides group were detected in all the samples, serving as positive control for the DNA extractions. It was the only group affected by the tillage in one of the plots, P29, with higher numbers in the intermediate level (W15) than in plots with the other tillage levels. Whether the intermediate level of tillage provides the perfect environment for the development of these nematodes or whether it was just an artifact remains to be determined. Similarly to the NF and the EPN community, the FLNs Acrobeloides group were higher in the heavier soil (P29). The abundance of all these organisms were positively correlated, suggesting a possible spatial association as previously reported (Campos-Herrera et al. 2012, 2013b). Finally, the FLNs were significantly higher in the monoculture, following the same trend as the EPN numbers and their activity. By consistently planting the same crop each season, the insects associated with the particular crop can build up their populations, and hence, hosts for both EPN and the FLNs are readily available.

Our low numbers of naturally occurring nematodes were in agreement with the low mortalities detected with sentinel larvae as soil bait. Low mortalities might be the results of the low numbers of IJs entering the host, but also of reduced infectivity. Studies on the virulence, reproductive potential and infection dynamics have shown that these variables are related to the EPN origin. For example, Spanish EPN isolated from agricultural areas showed poorer performance for these variables when compared with other isolates from natural areas and crop field edges, in some cases this was even valid for EPN belonging to the same species (CamposHerrera and Gutiérrez 2014; Campos-Herrera et al. 2007, 2008). In addition to the host limitation and perturbation stress promoted in these agricultural areas, the reduced EPN infectivity might be caused by the use of agrochemicals, such as pesticides. These chemicals can have sublethal effects and reduce reproduction (Gutiérrez et al. 2008) and hence limit the persistence of native EPN.

The results also show that the EPN suffer strong competition from other nematodes. Firstly, we regularly detected progeny of two species of nematodes in the same cadaver (H. megidis and S. kraussei-silvaticum), providing evidences for interspecific competition. Steinernematid mixed progenies are possible under laboratory conditions (Kondo 1989; Půža and Mráček 2009), but it is more likely that one species displaces the other, in particular with mixed infection of heterorhabditids and steinernematids (Alatorre-Rosas and Kaya 1990; Lewis et al. 2006). Mixed development will be particularly frequent between species with sympatric distribution (Půža and Mráček 2009). It is plausible that co-infections and mixed progenies have been largely overlooked in the past. Firstly, the morphological traits used to identify certain species overlap and it might be difficult to distinguish between closely related species. Secondly, is some cases, the molecular studies might use only few females to obtain the DNA for further analysis (Nguyen 2007), and hence, overlook the possible mixed infections in datasets from regional surveys. By identifying EPN using IJs progeny and checking with several species-specific primers/probe, it is now possible to detect these mixed progenies, even if the reproduction provides small quantities or the nematodes are closely related. The employment of the species-specific primers/probe might help us to significantly advance knowledge of the naturally occurring coinfections and possible interspecific dynamics occurring among EPN species.

In addition to the co-occurring EPNs, we observed EPN in combination with FLN in the cadavers. These FLN were able to multiply concomitantly with the EPN in most of the cases. The morphological and molecular identification showed the presence of Acrobeloides group and Oscheius spp. in our OG samples. Interestingly, none of next generation Galleria infections (MG samples) contained nematodes of the Acrobeloides group, confirming that these nematodes need an initial cadaver produced by EPN or other natural enemy activity to enter and multiply (Duncan et al. 2003; Campos-Herrera et al. 2012). However, we did detect Oscheius spp. in similar numbers as the corresponding EPN in the same MG samples, suggesting that these nematodes can reproduce with EPN in the same 
host. Recently, some species from the genus Oscheius have been labeled as entomopathogenic nematodes after revising their biology and ecological characteristics (Dillman et al. 2012). It is possible that the entomopathogenic nature of the nematodes belonging to Oscheius might be facultative. In our study, we observed cadavers producing both progenies from one host; however, whether these Swiss-native Oscheius spp. were able to kill an insect or just benefitted from the EPNkilled cadaver is still unknown. The ongoing studies on the characterization of these Swiss-native Oscheius spp. suggest the presence of a complex of species as described by Félix et al. (2001). Learning about the population dynamics of these nematodes in association with temporal and spatial pattern of EPN and other members of their soil food web will extend our knowledge of the ecological factors that determine the infectivity against key insect pests for native or augmented EPN.

The combined use of traditional and molecular tools to investigate the natural occurrence of EPN and selected natural enemies revealed that annual crop production and related managements such as tillage and crop rotation limit their occurrence to trace levels and reduce their detection in G. mellonella bait to below $4 \%$. In this ecological scenario, a strategy of augmentation biological control would be more profitable rather than conservation biological control. Optimizing the timing and application of EPN might provide alternatives to repeated applications. For example, adding EPN at planting could help protect the developing rhizosphere, reducing root herbivore damage in the early stages of the plant development. Also, applying EPN in combination with other beneficial organisms could result in synergistic effects that enhance plant performance. Using native EPN species, which might be locally adapted to the biotic and abiotic conditions, may enhance the effectiveness of an augmentative approach. Ongoing studies in Swiss annual field experiments are testing the potential of these possible improvements and will provide additional insight into the natural occurrence of EPN, their survival, and persistence.

Acknowledgments The authors thank Drs. L. W. Duncan, F.E. El-Borai, and D. Shapiro-Ilan for providing EPN and NF populations. The authors also appreciate the field assistance of Neil Villard during the first sampling time and the help provided by Dr. C. Praz and different members of the FARCE and E-vol in the molecular biology laboratory. We also thank the members of the
Soil and Vegetation laboratory (Universitz of Neuchâtel)for sharing their equipment and installations during the processing of the samples. This study was supported by the NRP68 program "Sustainable use of soil as a resource" (project no. 143065), Swiss National Science Foundation. G.J. was supported by a PhD assistantship from the University of Neuchâtel (Switzerland), and X. C. was awarded with a $\mathrm{PhD}$ fellowship from the Commission Fédérale de Bourses pour Etudiants Etrangères CFBE (Confédération Suisse).

Conflict of interest The authors declare that no competing interests exist.

\section{References}

Adams BJ, Nguyen KB (2002) Taxonomy and systematics. In: Gaugler R (ed) Entomopathogenic nematology. CABI Publishing, Wallingford, UK, pp 1-33

Alatorre-Rosas R, Kaya HK (1990) Interspecific competition between entomopathogenic nematodes in the genera Heterorhabditis and Steinernema for an insect host in sand. J Invertebr Pathol 55:179-188

Atkins SD, Clark I, Pande S, Hirsch PR, Kerry BR (2005) The use of real-time PCR and species-specific primers for the identification and monitoring of Paecilomyces lilacinus. FEMS Microbiol Ecol 51:257-264

Boemare N (2002) Biology, taxonomy and systematics of Xenorhabdus and Phtorhabdus. In: Gaugler R (ed) Entomopathogenic nematology. CABI Publishing, Wallingford, UK, pp 35-56

Campos-Herrera R, Gutiérrez C (2014) Steinernema feltiae intraspecific variability: infection process and sex-ratio. J Nematol 46:35-43

Campos-Herrera R, Escuer M, Labrador S, Robertson L, Barrios L, Gutiérrez C (2007) Distribution of the entomopathogenic nematodes from La Rioja (Northern Spain). J Invertebr Pathol 95:125-139

Campos-Herrera R, Gómez-Ros JM, Escuer M, Cuadra L, Barrios L, Gutiérrez C (2008) Diversity, occurrence, and life characteristics of natural entomopathogenic nematode populations from La Rioja (Northern Spain) under different agricultural management and their relationships with soil factors. Soil Biol Biochem 40:1474-1484

Campos-Herrera R, El-Borai FE, Stuart RJ, Graham JH, Duncan LW (2011a) Entomopathogenic nematodes, phoretic Paenibacillus spp., and the use of real time quantitative PCR to explore soil food webs in Florida citrus groves. J Invertebr Pathol 108:30-39

Campos-Herrera R, Johnson EG, El-Borai FE, Stuart RJ, Graham JH, Duncan LW (2011b) Long-term stability of entomopathogenic nematode spatial patterns measured by sentinel insects and real-time PCR assays. Ann App Biol 158:55-68

Campos-Herrera R, El-Borai FE, Larry LW (2012) Wide interguild relationships among entomopathogenic and freeliving nematodes in soil as measured by real time qPCR. J Invertebr Pathol 111:126-135

Campos-Herrera R, Ali JG, Díaz BM, Duncan LW (2013a) Analyzing spatial patterns linked to the ecology of herbivores 
and their natural enemies in the soil. Frontiers Plant Sci 4(378):1-18

Campos-Herrera R, Pathak E, El-Borai FE, Stuart RJ, Gutiérrez C, Rodríguez-Martín JA, Graham JH, Duncan LW (2013b) Geospatial patterns of soil properties and the biological control potential of entomopathogenic nematodes in Florida citrus groves. Soil Biol Biochem 66:163-174

Campos-Herrera R, Pathak E, El-Borai FE, Schumann A, AbdElgawad MMM, Duncan LW (2013c) New citriculture system suppresses native and augmented entomopathogenic nematodes. Biol Control 66:183-194

Campos-Herrera R, El-Borai FE, Ebert TA, Schumann A, Duncan LW (2014) Management to control citrus greening alters the soil food web and severity of a pest-disease complex. Biol Control 76:41-51

Dillman AR, Chaston JM, Adams BJ, Ciche TA, Goodrich-Blair H, Stock SP, Sternberg PW (2012) An entomopathogenic nematode by any other name. PLoS Pathogens 8:e1002527

Dolinski C, Choo HY, Duncan LW (2012) Grower acceptance of entomopathogenic nematodes: case studies on three continents. J Nematol 44:226-235

Duncan LW, Dunn DC, Bague G, Nguyen K (2003) Competition between entomopathogenic and free-living bactivorous nematodes in larvae of the weevil Diaprepes abbreviatus. J Nematol 35:187-193

Duncan LW, Graham JH, Zellers J, Bright D, Dunn DC, El-Borai FE, Porazinska DL (2007) Food web responses to augmenting the entomopathogenic nematodes in bare and animal manure-mulched soil. J Nematol 39:176-189

Duncan LW, Stuart RJ, El-Borai FE, Campos-Herrera R, Pathak E, Graham JH (2013) Modifying orchard planting sites conserves entomopathogenic nematodes, reduces weevil herbivory and increases citrus tree growth, survival and fruit yield. Biol Control 64:26-36

Ekmen ZI, Hazir S, Cakmak I, Ozer N, Karagoz M, Kaya HK (2010) Potential negative effects on biological control by Sancassania polyphyllae (Acari: Acaridae) on an entomopathogenic nematode species. Biol Control 54:166-171

El-Borai FE, Duncan LW, Preston JF (2005) Bionomics of a phoretic association between Paenibacillus sp. and the entomopathogenic nematode Steinernema diaprepesi. J Nematol $37: 18-25$

El-Borai FE, Brentu CF, Duncan LW (2007) Augmenting entomopathogenic nematodes in soil from a Florida citrus orchard: non-target effects of a trophic cascade. J Nematol 39: 203-210

Enright MR, Griffin CT (2004) Specificity of association between Paenibacillus spp. and the entomopathogenic nematodes, Heterorhabditis spp. Micro Ecol 48:414-423

Enright MR, McInerney JO, Griffin CT (2003) Characterization of endospore-forming bacteria associated with entomopathogenic nematodes, Heterorhabditis spp., and description of Paenibacillus nematophilus sp. nov. Inter J Syst Evol Microbiol 53:435-441

Félix M-A, Vierstraete A, Vanfleteren J (2001) Three biological species closely related to Rhabditis (Oscheius) pseudodolichura Körner in Osche, 1952. J Nematol 33:104-109

Freeman KR, Martin AP, Karki D, Lynch RC, Mitter MS, Meyer MS, Longcore JE, Simmons DR, Schmidt SK (2009) Evidence that chytrids dominate fungal communities at high-elevation soils. Proc Nat Acad Sci 106:18315-18320
Georgis R, Koppenhöfer AM, Lacey LA, Bélair G, Duncan LW, Grewal PS, Samish M, Tan L, Torr P, van Tol RWHM (2006) Successes and failures in the use of parasitic nematodes for pest control. Biol Control 38:103-123

Gray NF (1988) Fungi attacking bermiform nematodes. In: Poinar GO Jr, Jansson H-B (eds) Diseases of nematodes, vol II. CRC Press, Boca Raton, pp 3-38

Greenwood CM, Barbercheck ME, Brownie C (2011) Short term response of soil microinvertebrates to application of entomopathogenic nematode-infected insects in two tillage systems. Pedobiologia 54:177-186

Griffin CT (2012) Perspectives on the behavior of entomopathogenic nematodes from dispersal to reproduction: traits contributing to nematode fitness and biocontrol efficacy. J Nematol 44:177-184

Griffin CT, O’ Callaghan KM, Dix I (2001) A self-fertile species of Steinernema from Indonesia: fighter evidence of convergent evolution amongst entomopathogenic nematodes? Parasitology 122:181-186

Gutiérrez C, Campos-Herrera R, Jiménez J (2008) Comparative study of selected agrochemical products activity on Steinernema feltiae (Rhabditida: Steinernematidae). Biocontr Sci Technol 18:101-108

Hominick WM (2002) Biogeography. In: Gaugler R (ed), Entomopathogenic nematology, CABI Publishing, Wallingford, UK, pp: 115-143.

Jaffee BA, Strong DR (2005) Strong bottom-up and weak topdown effects in soil: nematode-parasitized insects and nematode-trapping fungi. Soil Biol Biochem 37:1011-1021

Jaffee BA, Ferris H, Scow KM (1998) Nematode-trapping fungi in organic and conventional cropping systems. Pytophatology 88:344-350

Jenkins WR (1964) A rapid centrifugal-flotation technique for separating nematodes from soil. Plant Dis Rep 48:492

Kaya HK, Aguillera MM, Alumai A, Choo HY, de la Torre M, Fodor A, Ganguly S, Hazir S, Lakatos T, Pye A, Wilson M, Yamanaka S, Yang H, Ehlers R-U (2006) Status of entomopathogenic nematodes and their symbiotic bacteria from selected countries or regions of the world. Biol Control 38 : 134-155

Kondo E (1989) Studies on the infectivity and propagation of entomogenous nematodes Steinernema spp. (Rhabditida: Steinernematidae) in the common cutworm, Spodoptera litura (Lepidoptera: Noctuidae). Bull Fac Agric Saga Univ 67:1-87

Kramer I, Hirschy O, Grunder JM (2001)Survey of baited insect parasitic nematodes from the Swiss lowland. In: EUR 19696COST ACTION 819. Developments in entomopathogenic nematode/bacterial research.Proceedings of the workshop at National University of Ireland Maynooth. 13-15 April 2000.

Larkin MA, Blackshields G, Brown NP, Chenna R, McGettigan PA, McWilliam H, Valentin F, Wallace IM, Wilm A, Lopez R, Thompson JD, Gibson TJ, Higgins DG (2007) ClustalW2 and ClustalX version 2. Bioinformatics 23:2947-2948

Lawrence JL, Hoy CW, Grewal PS (2006) Spatial and temporal distribution of endemic entomopathogenic nematodes in a heterogeneous vegetable production landscape. Biol Control 37:247-255

Lewis EE, Campbell J, Griffin C, Kaya HK, Peters A (2006) Behavioral ecology of entomopathogenic nematodes. Biol Control 38:66-79 
Liang W, Zhang X, Li Q, Jiang Y, Ou W, Neher DA (2005) Vertical distribution of bacterivorous nematodes under different land uses. J Nematol 37:254-258

Millar LC, Barbercheck M (2002) Effects of tillage practices on entomopathogenic nematodes in a corn agroecosystem. Biol Control 25:1-11

Mráček Z, Půža V, Nermut J (2014) Steinernema poinari sp. n. (Nematoda: Steinernematidae) a new entomopathogenic nematode from the Czech Republic. Zootaxa 3760:336-350

Nguyen KB (2007) Methodology, morphology and identification. In: Nguyen KB, Hunt DJ (eds.) Entomopathogenic nematodes: systematics, phylogeny and bacterial symbionts, Nematology Monographs and Perspectives, Vol. 5, LeidenBoston: Brill, Leiden (The Netherlands), pp: 59-119.

Nguyen KB, Hunt DJ Mraček Z (2007) Steinernematidae: species descriptions. In: Nguyen KB, Hunt DJ (eds.) Entomopathogenic nematodes: systematics, phylogeny and bacterial symbionts. Nematology Monographs and Perspectives, vol. 5, Leiden-Boston: Brill, Leiden (The Netherlands), pp: 121-609.

Pathak E, El-Borai FE, Campos-Herrera R, Jonhson EG, Stuart RJ, Graham JH, Duncan LW (2012) Use of real-time PCR to discriminate predatory and saprophagous behavior by nematophagous fungi. Fungal Biol 116:563-573

Persmark L, Blank A, Jansson H (1996) Population dynamics of nematophagous fungi and nematodes in arable soil: vertical and seasonal fluctuations. Soil Biol Biochem 28:1005-1014

Půža V, Mráček Z (2009) Mixed infection of Galleria mellonella with two entomopathogenic nematodes (Nematoda: Rhabditida) species: Steinernema affine benefits from the presence of Steinernema kraussei. J Invertebr Pathol 102:40-43

Rooij-van D, der Goes PCEM, van der Putten WH, van Dijk C (1995) Analysis of nematodes and soil-borne fungi from Ammophila arenaria (Marram grass) in Dutch coastal foredunes by multivariate techniques. Eur J Plant Pathol 101:149-162

Rozen S, Skaletsky HJ (2000) Primer3 on the WWW for general users and for biologist programmers. In: Krawetz S, Misener
S (eds.), Bioinformatics methods and protocols: methods in molecular biology. Humana Press. Totowa, (NJ, USA), pp: 365-386.

Steiner WA (1996) Distribution of entomopathogenic nematodes in the Swiss Alps. Rev Suisse Zool 103:439-452

Stuart RJ, Barbercheck ME, Grewal PS, Taylor RAJ, Hoy CW (2006) Population biology of entomopathogenic nematodes: concepts, issues, and models. Biol Control 38:80-102

Sturhan D, Spiridonov S, Mrácek Z (2005) Steinernema silvaticum sp. n. (Rhabditida: Steinernematidae), a new entomopathogenic nematode from Europe. Nematology 7: 227-241

Sugar DR, Murfin KE, Chaston JM, Andersen AW, Richards GR, de Léon L, Baum JA, Clinton WP, Forst S, Goldman BS, Krasomil-Osterfeld KC, Slater S, Stock SP, Goodrich-Blair H (2012) Phenotypic variation and host interactions of Xenorhabdus bovienii SSe2004, the entomopathogenic symbiont of Steinernema jollieti nematode. Environ Microbiol 14:924-939

Torr P, Spiridonov SE, Heritage S, Wilson MJ (2007) Habitat associations of two entomopathogenic nematodes: a quantitative study using real-time quantitative polymerase chain reactions. J Anim Ecol 76:238-245

Ulug D, Hazir S, Kaya HK, Lewis E (2014) Natural enemies of natural enemies: the potential top-down impact of predators on entomopathogenic nematode populations. Entomological Entomol 39:462-469

White GF (1927) A method for obtaining infective nematode larvae from cultures. Science 66:302-303

Woodring, J.L., Kaya, H.K., 1988. Steinernematid and Heterorhabditid nematodes: a handbook of techniques. Southern Coop. Ser. Bull., Arkansas Agric. Exp. Sta. Fayetteville, Arkansas.

Zhang LM, Liu XZ, Zhu SF, Chen SY (2006) Detection of the nematophagous fungus Hirsutella rhossiliensis in soil by real-time PCR and parasitism bioassay. Biol Control 36: 316-32 